\title{
Experimental experience of cold starting a spark ignition UAV engine using low volatility fuel
}

\author{
P.R.Hooper \\ School of Engineering, Auckland University of Technology, St Paul Street, Auckland, 1010, New Zealand
}

\begin{abstract}
Purpose - The purpose of this paper is to present results of practical experience of cold starting a gasoline engine on low volatility fuel suitable for Unmanned Air-Vehicle (UAV) deployment.

Design/methodology/approach - Experimental research and development via dynamometer testing of systems capable of achieving cold start of a spark ignition UAV engine on kerosene JET A-1 fuel.

Findings - Repeatable cold starts have been satisfactorily achieved at ambient temperatures of $5^{\circ} \mathrm{C}$. The approximate threshold for warm engine restart has also been established

Practical implications - For safety and supply logistical reasons the elimination of the use of gasoline fuel offers major advantages not only for UAVs but for other internal combustion engine powered equipment to be operated in military theatres of operation. For gasoline crankcase scavenged two stroke cycle engines this presents development challenges in terms of modification of the lubrication strategy, achieving acceptable performance characteristics and the ability to successfully secure repeatable engine cold start.

Originality/value - The majority of UAVs still operate on gasoline based fuels. Successful modification to allow low volatility fuel operation would address single fuel policy objectives
\end{abstract}

Keywords Cold starting, internal combustion engine, heavy fuel UAV engine, single fuel policy

Paper type Technical paper

\section{Introduction}

Unmanned Aerial Systems (UAS) or UAVs are becoming increasingly exposed to both civil and military environments (Austin, 2010). The adoption of a single fuel policy as discussed by Owens et al (1989) has been a key objective for quite some time for military applications (Donaldson, 2011). Successful implementation would achieve simplification of supply logistics and improved safety especially with elimination of the presence of gasoline fuel from military theatres of operation. Operation of engines on lower volatility fuels is required to meet these objectives. For UAVs this has stimulated research and development of engines to meet this requirement using a range of approaches employing adapted conventional two stroke engines as demonstrated by the work of Duddy et al (2011), Hooper and Hooper (1996), Blank et al (2001) and Cathcart et al (2006). Alternative engine design methodologies have also been developed using novel techniques as discussed by Stone (2012), Hooper and Hooper (1996), Hooper (2001, 2005) and Hooper et al (2011, 2012). Opposed piston designs have been proposed by Kalkstein et al (2006) and there have been cases considering four stroke engines as presented by Cathcart et al (2005).

Unmanned Air Vehicles for low to medium altitude aircraft are usually comprised of low mass systems to meet the demands of their effective and efficient operation. Accommodating a change to a compression ignition engine solution could readily allow operation on heavy or low volatility fuels. Examples of this can be seen from the modelling and experimental work of Mattarelli et al $(2010,2011)$ and as published by Trunzo et al (2012). Compression ignition engines however usually impose an unacceptably high propulsion system mass penalty for UAVs.

Suitable low volatility fuels include; diesel, AVTUR, NATO F34, JET A-1, JP-5 or JP-8. The thermodynamic and operational characteristics of these fuels are well understood (CRC, 2004) but they were designed for use in turbine or compression ignition engines rather than engines designed for spark ignition. Turbine engines for anything but high altitude UAVs are usually limited by an inability to loiter at a low enough cruise speed and often suffer from high specific fuel consumption using small capacity engines. The remaining alternative is therefore to develop spark ignition engines capable of operation on low volatility fuels whilst achieving satisfactory levels of efficiency and maintaining acceptable mission endurance.

The experimental study reported within this paper discusses systems developed to successfully allow a crankcase scavenged two-stroke cycle engine to operate on JET A-1 aviation turbine fuel (Goodger, 1975, 1980). Work included modification of the engine to allow development of a range of fuel delivery methods requiring changes to the lubrication system of the standard engine to enable operation on heavy fuels. Systems were developed to allow repeatable cold 
starting suitable for a UAV launcher environment. The ability of the engine to successfully respond to demands for hot restarting after recent operation was also explored.

\section{Methodology}

The WAE342 engine as detailed by Meggit Defence Systems (2014) was originally designed by Weslake Aero-Marine Ltd. Production passed from Weslake to Normalair Garret Ltd where the engine saw application for Unmanned Air Vehicle use for a number of UAVs including "Skeet", "Snipe", "Spectre" and the British Army "Phoenix" UAV system developed originally by GEC-Marconi Avionics and latterly by BAE Systems Ltd as discussed by Austin (2010). A sectional arrangement of the WAE342 engine is shown for reference in Figure 1.

Figure 1. Sectional arrangement of the WAE342 engine

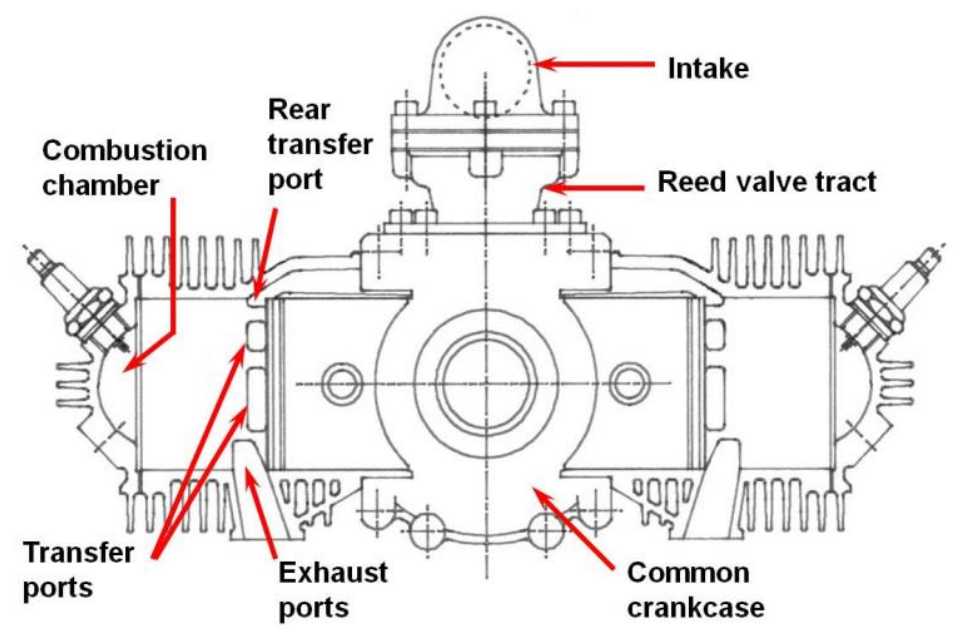

In horizontally opposed flat twin cylinder two stroke cycle engines the cylinders fire simultaneously. As can be seen in Figure 1 the combustion chamber is axi-symmetric and is located in a detachable cylinder head with an offset spark plug location. Dual spark plug options have been available for the engine. The basic form of the engine uses a single diaphragm carburettor however modification to apply inlet fuel injection has been used on more advanced UAVs such as Phoenix. For gasoline injection the fuel injector supplies fuel into the single reed valve controlled entrance to the crankcase. The reed valve comprises six spring steel petals mounted on an elastomer coated die-cast housing. The cylinders are designed with five transfer ports and two exhaust ports with a centrally located bridge. General design data for the WAE342 is reproduced for reference in Table 1.

Table 1. General Engine data - WAE342 Engine

\begin{tabular}{|lc|l|}
\hline Swept Volume & $\left(\mathrm{cm}^{3}\right)$ & 342 \\
\hline No. of cylinders & & 2 \\
\hline Cylinder arrangement & & Horizontally opposed twin \\
\hline Bore & $(\mathrm{mm})$ & 66 \\
\hline Stroke & $(\mathrm{mm})$ & 50 \\
\hline Connecting rod centres & $(\mathrm{mm})$ & 82 \\
\hline Fuel & & $\begin{array}{l}98 \text { RON gasoline (with 4\% added } \\
\text { Silkolene COMP-2 two-stroke oil) }\end{array}$ \\
\hline Lubrication & & Total loss (Pre-mixed fuel) \\
\hline
\end{tabular}


A schematic of the dynamometer test installation is shown in Figure 2.

Figure 2. Schematic of WAE342 Engine Experimental Dynamometer Test Facility

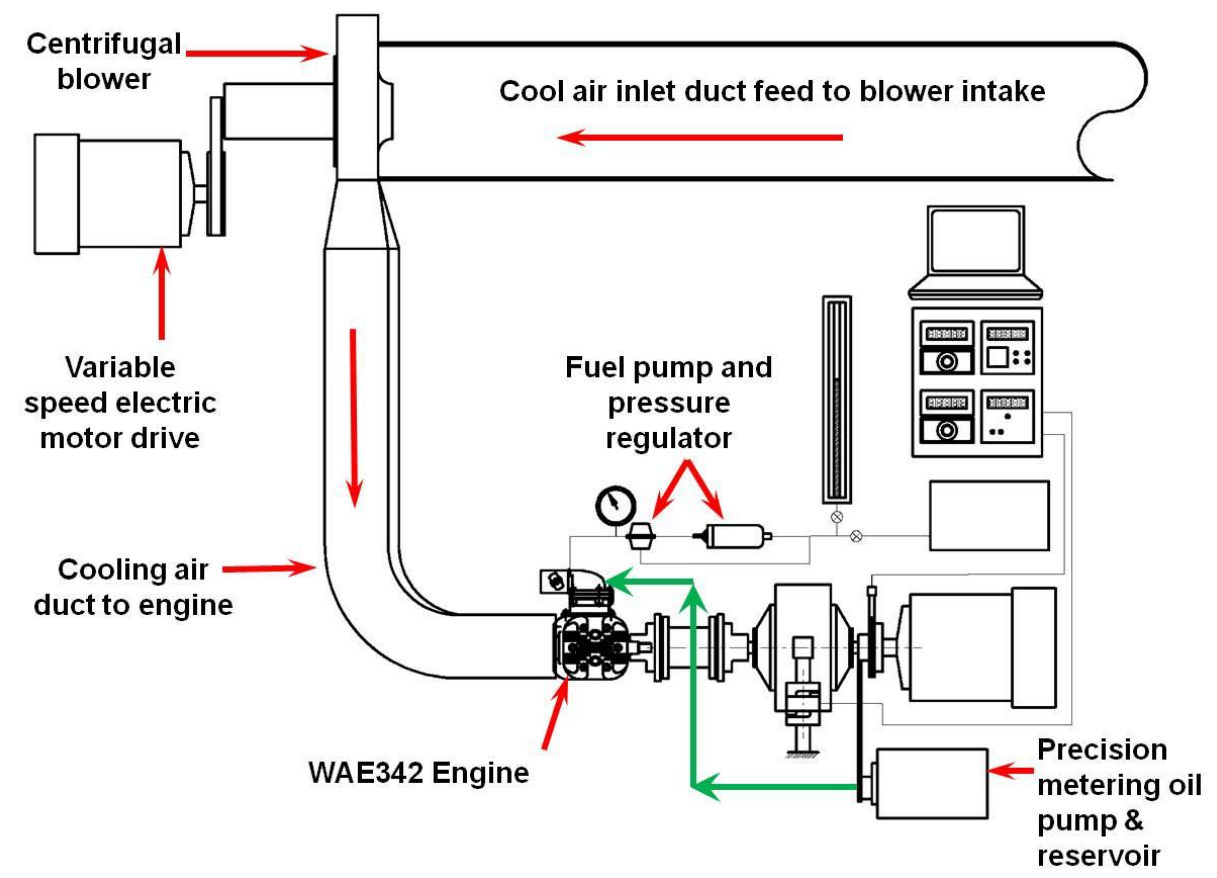

The air cooled WAE342 cooling fins were enclosed in close fitting cowls with cooling air supplied by a centrifugal blower to the cowls via flexible 150mm diameter ducts as shown in Figure 2 and Figure 3. A three phase electric motor and belt drive together with a variable speed/three phase frequency controller allowed adjustable air flow to be supplied to the engine cylinders. A differential pressure switch monitoring air flow pressure was used to provide engine ignition cut out should the cooling system malfunction for any reason and thus avoiding engine seizure. Air intake to the centrifugal blower was supplied from outside the test cell to avoid re-ingestion of exhaust cooling air as shown in Figure 2.

Figure 3. WAE342 Dynamometer test installation



The standard WAE342 engine is designed to operate with a pre-mixed oil supply within the gasoline fuel. For test operation using fuel injection into the transfer ports a separate lubrication system was required. A Bosch oil metering 
system was adapted for this purpose. The system comprises an oil storage tank supplying a precision metering pump. The outlet from the pump is fed directly to the WAE342 engine intake manifold supplying the reed valve and common crankcase. The output flow rate was mapped for varying throttle openings and a dual throttle actuation system was calibrated to provide sufficient oil flow from the pump when the engine was operating at full throttle. With knowledge of the typical fuel flow supply to the carburetted engine and therefore the proportion of oil (4\%) the target output from the pump can therefore be calculated. Flow requirements were derived on this basis and measured with the engine operating on pre-mix carburetted fuel whilst the pump output was monitored and adjusted.

The WAE342 engine normally operates with relatively short open stub exhausts. In order to retain as close a correlation with normal operating conditions short stubs were fabricated to feed a close fitting (but not sealed) exhaust collector box/muffler offering minimal flow resistance. From the end of the collector exhaust gases were ducted away into the test cell gas extraction system. The engine was started using a three phase electric motor and disengage-able clutch drive system cranking the engine axially through the dynamometer shaft.

\section{Baseline Engine Experimental Testing}

The WAE342 engine was originally designed for operation with a diaphragm carburettor fuel system. Some examples of the engine have been developed with fuel injection such as the British Army Phoenix system. This used a single injector supplying fuel into the inlet manifold just upstream of the reed valve. In order to operate on kerosene fuel the engine was modified to allow the installation of electro-magnetic fuel injectors.

Gasoline baseline testing with the standard Mikuni carburettor was established to 7000 RPM with and without the low resistance exhaust system muffler. The fuel used was 98RON gasoline with 4\% added Fuchs Silkolene Comp-2 SAE40 two-stroke oil as defined by Fuchs (2014) for carburettor based tests, whilst testing with indirect fuel injection was performed with 98RON gasoline and separate metered supply of lubricating oil into the intake manifold just upstream of the engine reed valve. The results of initial baseline tests are shown in Figure 4.

Figure 4. Initial baseline test data recorded using pre-mix gasoline carburettor fuelling

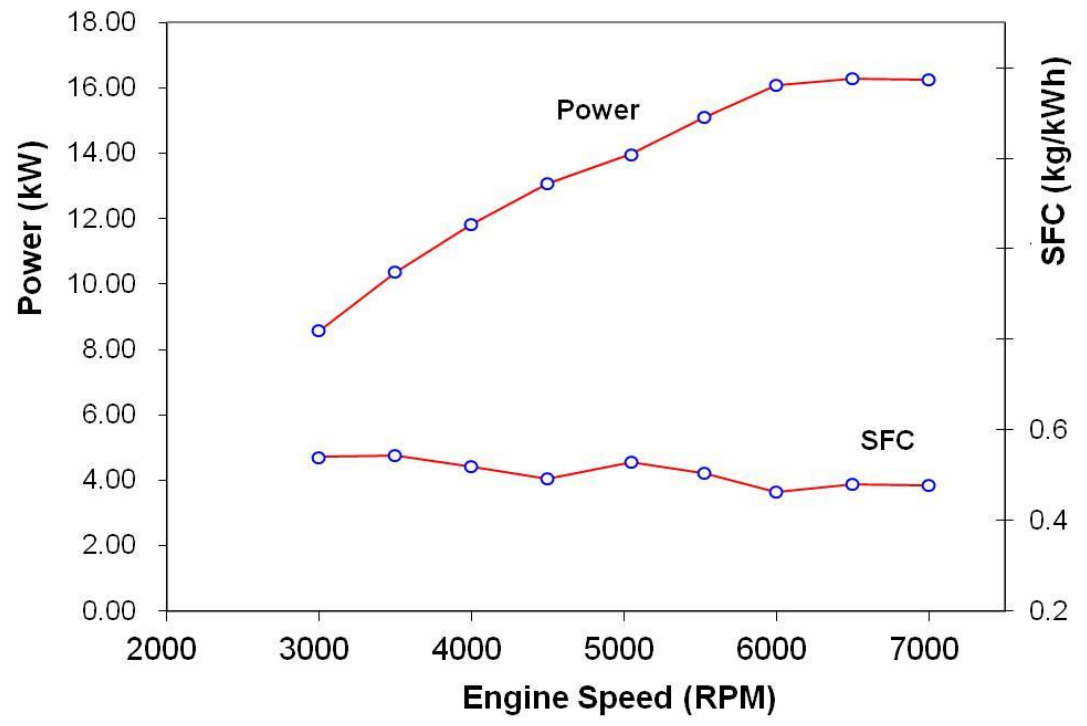

On reference to Figure 4, maximum power was recorded at 6500 RPM and observed to be $16.27 \mathrm{~kW}$. The minimum full load SFC was recorded at $0.464 \mathrm{~kg} / \mathrm{kWh}$ at $6000 \mathrm{RPM}$. 


\section{Rear Transfer Port Fuel Injection (RFI)}

The engine was modified to allow fuel injectors to be installed to supply fuel to the rear transfer ports of each cylinder. Performance development to explore the effects of operation on kerosene JET A-1 was established across the full operating speed range at full load as summarised in Figure 5.

Figure 5. Comparison of kerosene JET A-1 and pre-mix gasoline full load performance

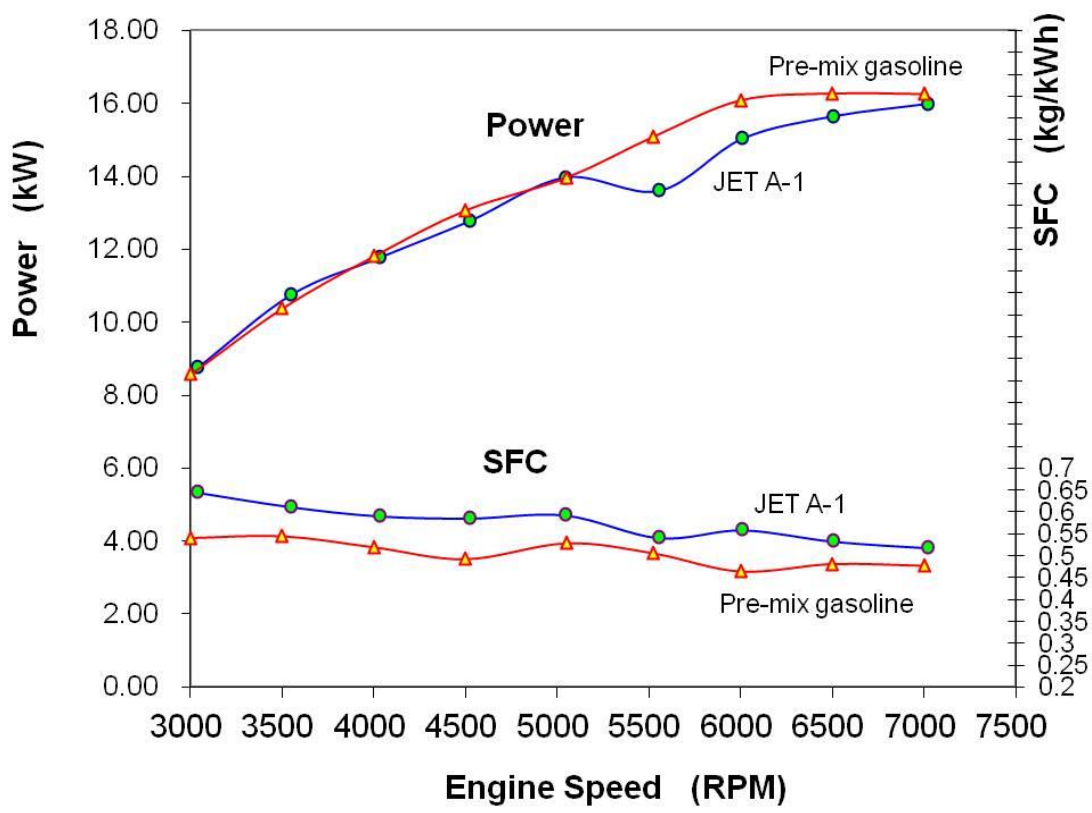

At 5000 RPM using pre-mix gasoline or kerosene JET A-1 the power output can be seen to be the same. SFC however using JET A-1 is increased to $0.593 \mathrm{~kg} / \mathrm{kWh}$ compared with $0.528 \mathrm{~kg} / \mathrm{kWh}$ with pre-mix gasoline/oil mixture. At the maximum engine speed tested of 7000 RPM gasoline performance was $16.26 \mathrm{~kW}$ with a corresponding SFC of 0.477 $\mathrm{kg} / \mathrm{kWh}$ compared with $16.0 \mathrm{~kW}$ and an SFC of $0.518 \mathrm{~kg} / \mathrm{kWh}$ using JET A-1 kerosene. Over the range of speeds tested the thermal efficiency varies from $15.39 \%$ to $18.04 \%$ using gasoline and from $12.92 \%$ to $16.09 \%$ with JET A-1. Due to the lower volatility of JET A-1 compared with gasoline the compression ratio of the engine was reduced to try to avoid the onset of detonation. The standard gasoline trapped compression ratio (after exhaust port closure) is 7.1:1. This was reduced to 5.65:1. Even at this reduced level it was possible to observe detonation so ignition timings were retarded from those achievable with gasoline. The JET A-1 data is therefore knock limited which may explain elements of the observed higher SFC and performance reduction.

\section{Effect of Kerosene Density on Specific Fuel Consumption}

A comparison of fuel properties for gasoline and JET A-1 is reproduced in Table 2. The data for JET A-1 is sourced from the published work of CRC (2004) and the relevant gasoline properties are from data published by Fardad and Ladommatos (1999) and Pulkrabek (2004). The density of the JET A-1 fuel is from the data supplied by Shell (measured at $15^{\circ} \mathrm{C}$ ) for the dynamometer test programme fuel batches.

Table 2. Comparison of Fuel Properties

\begin{tabular}{|lr|c|c|}
\hline Fuel & & Gasoline & JET A-1 \\
\hline Density & $\left(\mathrm{kg} / \mathrm{m}^{3}\right)$ & 750 & $793.2-799.9$ \\
\hline Lower Heat Value & $(\mathrm{MJ} / \mathrm{kg})$ & 43.0 & 43.2 \\
\hline Stoichiometric Air:Fuel Ratio & 14.6 & 14.71 \\
\hline
\end{tabular}


It should be pointed out, that for the same given volumetric flow of fuel and identical power, the calculated specific fuel consumption using kerosene JET A-1 will be higher than that for gasoline on a mass basis due to its higher density as can be seen in Figure 2. For example if the performance recorded using gasoline was repeated identically with kerosene (density $797.7 \mathrm{~kg} / \mathrm{m}^{3}$ ) with an identical fuel volume flow rate and power, a $6.6 \%$ increase in specific fuel consumption would be calculated.

All experimental test data recorded from the WAE342 test engine has been corrected for Standard Atmospheric conditions to SAE Standard J1349 (SAE, 1995).

\section{Engine Cold Starting}

Experimentation to investigate the possibility of achieving successful engine cold starting was conducted with the WAE342 engine that had previously been used to explore JET A-1 fuel performance development as summarized in Figure 5. Following consultations with manufacturers conventional automotive type compression ignition engine glow plugs were selected. The initial location of the glow plug for testing is shown in Figure 6.

Figure 6. Initial Glow plug installation - WAE342 Engine

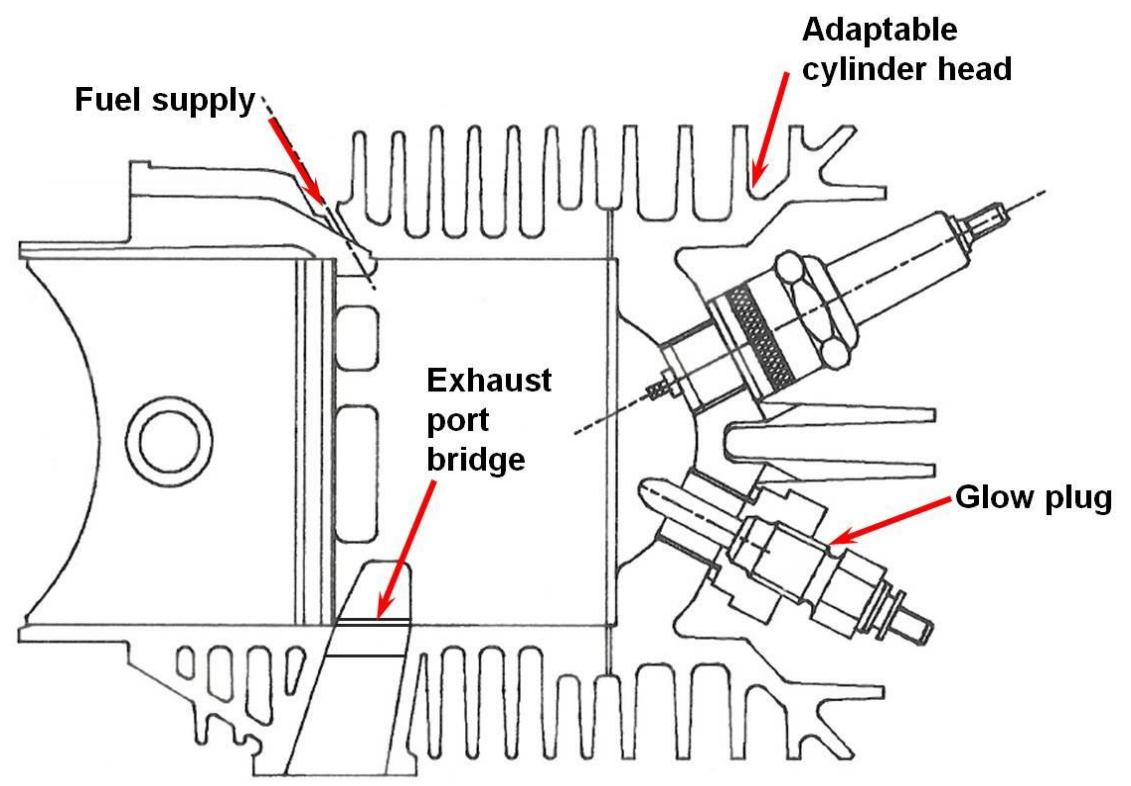

Initially a start was achieved within 10 seconds however it was observed that subsequent starts were increasingly reluctant and eventually impossible. It is possible that a small quantity of gasoline may have been present within the fuel injection system (perhaps lodged in wells within the fuel pump and/or pressure regulator). This may have therefore diluted the kerosene fuel supply to the injectors, hence effectively raising the fuel volatility and achieving successful ignition.

After purging any possibility of gasoline dilution, cold starts were then observed to be possible only by application of an aerosol spray of engine starting fluid (diethyl ether) into the engine air intake. A new approach was therefore required and the possibility that the fuel charge may be wetting the spark plug prior to reaching the glow plug was considered. This was explored by relocating the glow plug to the position shown by the spark plug in Figure 6 and locating the spark plug in the position vacated by the glow plug. This unfortunately did not resolve the failure to achieve engine start up.

Optimum fuel efficiency in loop-scavenged two-cycle engines is often achieved by ensuring that the fresh air/fuel charge is scavenged away from the exhaust side of the cylinder. A change of experimental approach was therefore adopted to see whether the glow plug would successfully ignite or at least preheat the initial cold kerosene fuel charge prior to the spark ignition. Unfortunately successful cold starting was still not possible by this method. New injector nozzles were therefore made after further consideration. The nozzles comprised an integral glow plug, such that the glowing tip protrudes into the 
fuel air stream just downstream of the fuel injector delivery. Rapid heating of the cold kerosene JET A-1 fuel and air prior to entry into the cylinder is achieved by this method. It was then found that a 30 second preheat period applied to both the injector nozzle and cylinder head glow plugs (i.e. two glow plugs per cylinder) successfully achieved cold starts but only after relatively long periods of engine cranking.

Further experimentation by providing a short cranking period (of 3-5 seconds) after an initial injector glow plug preheat with fuel supplied to the injectors appeared to result in improved response. It was thought that this method may be allowing time for sufficient vapourisation of the initial cold fuel charge thereby giving more rapid time to achieve combustion. Total preheat periods of $2 \mathrm{~min} 45 \mathrm{~s}$ were found to be required at ambient temperatures of $6.5^{\circ} \mathrm{C}$.

After observations of the improved success offered by longer glow plug heating periods, it was decided to leave the glow plugs on for longer durations than the previous times of typically 30 seconds. Following further experimentation with initial fuel enrichment settings repeatable instantaneous starts were achieved from ambient temperatures of $5^{\circ} \mathrm{C}$ after 2 minute preheat periods. It was also observed that this was possible with sole aid of the injector nozzle glow plug alone. Reduced preheat periods of $1 \mathrm{~min} 45 \mathrm{~s}$ to $1 \mathrm{~min} 30 \mathrm{~s}$ have been observed to give successful cold starts as ambient temperature increases to in excess of $12^{\circ} \mathrm{C}$. The final configuration showing the fuel delivery nozzle and integral glow plug can be seen for reference in Figure 7.

Figure 7. Final configuration of glow plug installation - WAE342 Engine

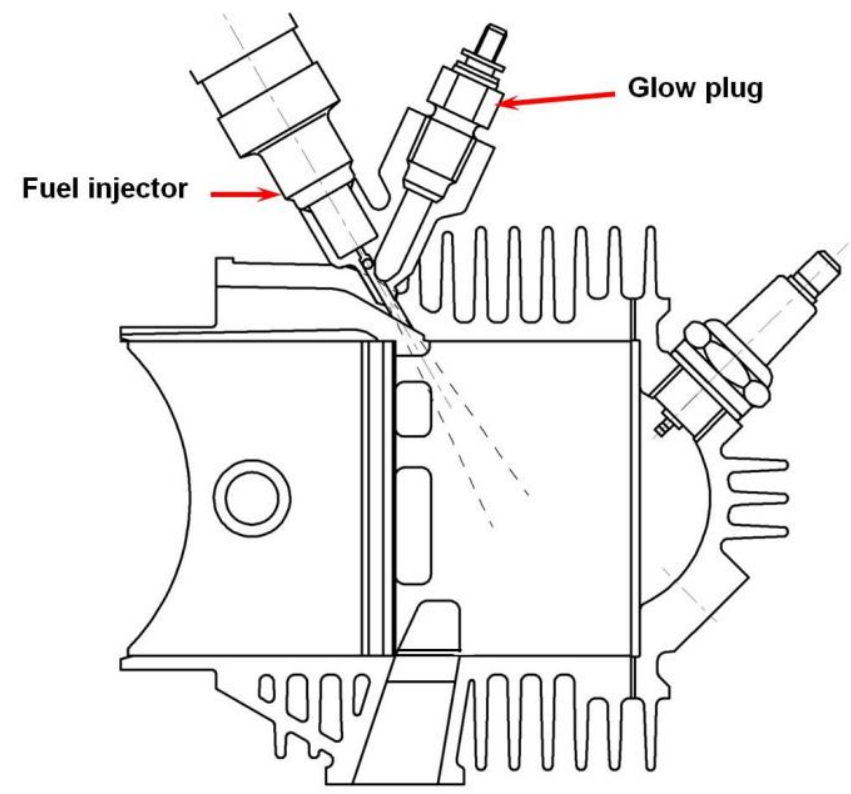

Data logging of engine and fuel system parameters such as, throttle position, engine and air intake temperatures, engine speed and injector pulse widths were recorded against elapsed time during tests. In excess of 30 log files were captured after the successful starting system had been established. Data from a typical output log file is shown in Figure 8. 
Figure 8. Engine cold start using kerosene JET A-1 fuel - WAE342 Engine

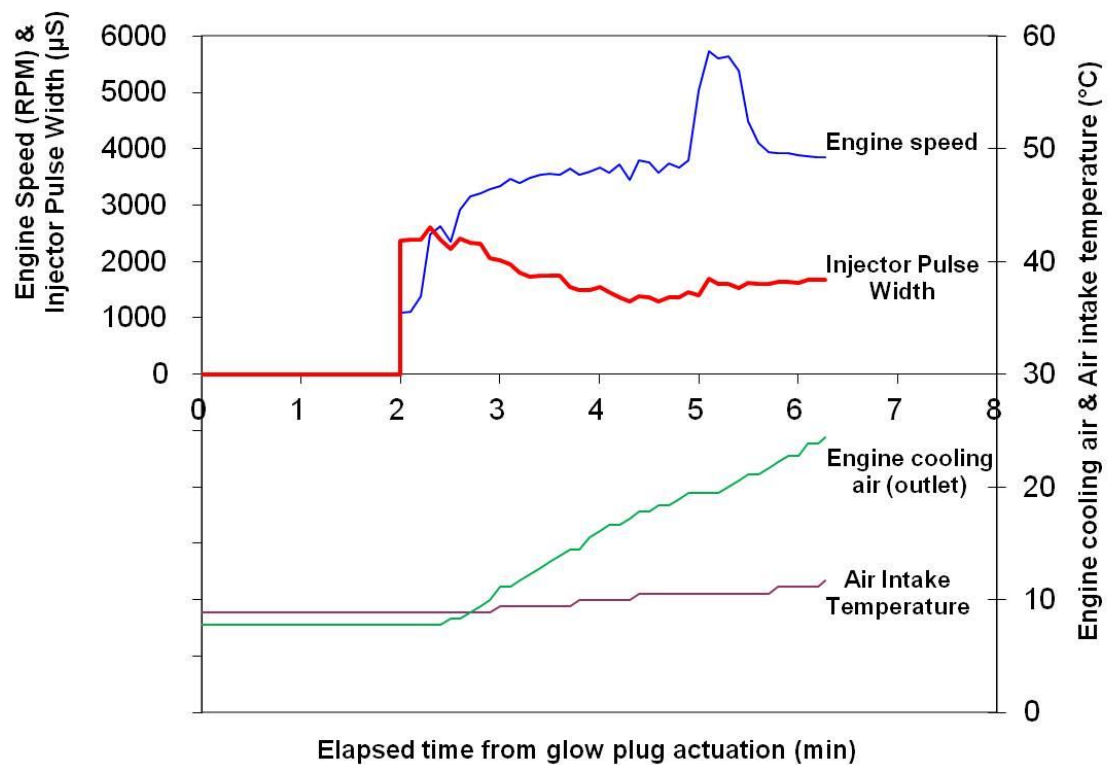

Experimentation was also performed using an inline fuel heater unit as typically used on diesel vehicles in cold climatic conditions. This was located in the fuel supply line before the injectors, thereby preheating the fuel prior to entry to the injectors. Starting response times were not observed to show any significant improvement over glow plug only actuated cold starts.

\section{Engine Hot Starts}

After performing cold starts, further tests were carried out to examine the minimum engine temperature at which restarting could be achieved without re-activating the glow plugs. With cylinder head temperatures as low as $50^{\circ} \mathrm{C}$, unassisted restarts were successful. At $45^{\circ} \mathrm{C}$, it was observed that glow plug assistance became necessary.

\section{Discussion}

Significant research and development in terms of fuel delivery methods, compression ratio and ignition timing modifications in order to achieve satisfactory heavy fuel operation of spark ignition UAV engines normally designed for gasoline (or gasoline/oil) fuels has been done prior to this cold start study. This prior work is of limited advantage if the engines are not able to successfully start from cold on heavier fuels such as kerosene JET A-1. If successful cold starting on heavy fuel was not possible, small amounts of gasoline or high volatility starting fluids would be required. This would therefore not fully secure the objectives of the single fuel policy thereby presenting supply logistics and localised safety issues.

The feasibility of cold starting a crankcase scavenged two stroke engine on kerosene JET A-1 fuel has been successfully demonstrated to be possible during this programme of work with the assistance of external electrically powered glow plug technology typically employed on compression ignition diesel engines for cold start assistance. From dynamometer experimentation cold starts have been achieved from ambient temperatures of $5^{\circ} \mathrm{C}$ with glow plug preheat times of 2 minutes. Progressively less preheating period is required as ambient temperatures increase.

The preheat times are of course appreciably higher than would normally be experienced using an automotive diesel engine, however the times observed within this study are not expected to cause any significant delays to achieving 
satisfactory air borne deployment of the air vehicle. The procedures for launch of a UAV can be quite lengthy with extensive ground checks to ensure integrity of the air vehicle systems. Furthermore the available power supply at a UAV launcher means that electrical power for glow plug activation should not present a major challenge. At sub zero temperatures it is possible that external engine heating may be required; however, such methods are already used to cold start some existing UAV engines on gasoline fuel.

An inlet fuelled two stroke cycle engine operating on pre-mixed gasoline/oil fuel requires additional complexity in terms of the separation of the lubrication system. This requires installation of a separate oil reservoir and oil pump to deliver precision metered quantity of lubricant into the engine. Such technology is not uncommon on modern two stroke engines for automotive or marine applications; however this does present an additional challenge to the UAV system designers. The complication can be avoided by using more advanced UAV two-stroke cycle engines such as segregated scavenging engines as discussed by Stone (2012) and Hooper et al $(2011,2012)$. In these forms of two stroke engines the lubrication system and air delivery systems are separated from each other and the oil circulation system forms an integral part of the engine design in a similar method achieved by four stroke engines with re-circulatory lubricant flow control.

\section{Conclusions}

The ability to start the WAE342 engine from cold (typical UK ambient) using kerosene JET A-1 has been demonstrated with the assistance of conventional diesel engine glow plug technology. Cold starts have been satisfactorily achieved at ambient temperatures of $5^{\circ} \mathrm{C}$ with glow plug preheat times of 2 minutes. As ambient temperatures increase a reduction in the necessary preheating period was observed. Restarting of engines on kerosene JET A-1 after prior operation was also successfully achieved. Unassisted restarts (no glow plug actuation) were successful with cylinder head temperatures as low as $50^{\circ} \mathrm{C}$. Hot starting with cylinder head temperatures of $45^{\circ} \mathrm{C}$ revealed that glow plug assistance was again required to achieve engine restart.

\section{References}

Abis, A., Schwab, C., Kirchberger, R., and Eichlseder, H. (2013) - "An Innovative Two-Stroke Twin-Cylinder Engine Layout for Range Extending Application," (SAE Technical Paper 2013-32-9133, 2013)

Austin, R (2010) - "Aircraft Systems - UAS Design, Development and Deployment" (Wiley International ISBN 978-0-47005819-0 (2010))

Blank, D.A., Pouring, A.A., and Lu, J. (2001) - "Qualitative Flow Field Studies of Combustion in I.C. Engines Using a Simplified Sonex Bowl-in-Piston Geometry” (SAE Paper No. 2001-26-0021 (2001))

Cathcart, R., Tubb, J., Dickson, G., and Schmidt, B. (2006) - "Development of Lightweight 2-Stroke and 4-stroke Heavy Fuel UAV Engines" (AUVSI International Conference, Orlando, 2006)

Cathcart, R., Dickson, G., and Ahern, S. (2005) - "The Application of Air-Assist Direct Injection for Spark-ignited Heavy Fuel 2-Stroke and 4-stroke Engines" (SETC Small Engine Technology Conference, Bangkok, 2005)

CRC Report (2004) - "Handbook of Aviation Fuel Properties"- CRC Report No. 635, 3rd Edition Coordinating Research Council Inc, Alpharetta, GA/ SAE International, Warrendale, PA

Donaldson, P. (2014) - Article "Heavy Duty" (Unmanned Vehicles, Shephard Group, June/July 2011 Vol 16 No.3 pp. 36 38)

Duddy, B.J., Lee, J., Walluk, M., and Hallbach, D. (2011) - "Conversion of a Spark-Ignited Aircraft Engine to JP-8 Heavy Fuel for use in Unmanned Aerial Vehicles" (SAE Paper No. 2011-01-0145 (2011))

Fardad, D. and Ladommatos, N. (1999) - "Evaporation of Hydrocarbon Compounds, including Gasoline and Diesel Fuel, on Heated Metal Surfaces" (Proc. IMechE Vol. 213 Part D: Journal of Automobile Engineering D00199)

Fuchs Lubricants website (2014) - http://www.fuchslubricants.com/silkolene [accessed 17 July 2014]

Goodger, E.M. (1980) - "Alternative Fuels - Chemical Energy Resources" (Macmillan Press ISBN 0-333-25813)

Goodger, E.M. (1975) - "Hydro-carbon fuels" (Macmillan Press 1975) 
Hooper, B and Hooper, P.R. (1996) - "Initial Heavy Fuel Development of Stepped Piston and Crankcase Scavenged Twocycle Engines" (12th International RPV Conference, Bristol University, 9-11 September 1996)

Hooper, P.R. (2001) - "Initial Development of a Multi-Fuel Stepped Piston Engine for Unmanned Aircraft Application" (Aircraft Engineering and Aerospace Technology Volume 73 Number 5, 2001, pp.459-464 MCB University Press ISSN 0002-2667)

Hooper, P.R. (2005) - "Stepped Piston Engines for Multi-Fuel UAV Application" (IMechE Conference on Propulsion Systems for Unmanned Aircraft, Bristol, 14 April 2005)

Hooper, P.R., Al-Shemmeri, T and Goodwin, M.J. (2011) - "Advanced modern low emission two-stroke cycle engines" (Proceedings of the Institution of Mechanical Engineers, Part D: Journal of Automobile Engineering. Vol. 225 No.11, November 2011)

Hooper, P.R., Al-Shemmeri, T and Goodwin, M.J. (2012) - "An experimental and analytical investigation of a multi-fuel stepped piston engine" (Journal of Applied Thermal Engineering April 2012) $<\mathrm{http}: / /$ dx.doi.org/10.1016/j.applthermaleng.2012.04.034>

Kalkstein, J., Röver, W., Campbell, B., Zhong, L., Huang, H., Ping Liu, J., Tatur, M., Geistert, A., and Tusinean, A. (2006) - "Opposed Piston Opposed Cylinder (opoc ${ }^{\mathrm{TM}}$ ) 5/10 kW Heavy Fuel Engine for UAVs and APUs" (SAE Paper No. 200601-0278 SAE 2006 World Congress \& Exhibition, Detroit April 2006)

Mattarelli, E., Rinaldini, C., and Baldini, P. (2014) - "Modeling and Experimental Investigation of a 2-Stroke GDI Engine for Range Extender Applications," (SAE Technical Paper 2014-01-1672, (2014), doi:10.4271/2014-01-1672.)

Mattarelli, E., Paltrinieri, F., Perini, F., Rinaldini, C.A., and Wilksch, M. (2010) - "2-Stroke Diesel Engine for Light Aircraft: IDI vs. DI Combustion Systems" (SAE Paper No. 2010-01-2147 (2010))

Mattarelli, E., Rinaldini, C.A., and Wilksch, M. (2011) - "2-Stroke High Speed Diesel Engines for Light Aircraft" (SAE Paper No. 2011-24-0089 (2011))

Meggitt Defence Systems (2014) - WAE342 engine data sheet

<http://www.meggittdefenceuk.com/PDF/MDS\%20342\%202014\%20Mod\%201.pdf> [accessed 21 July 2014]

Owens, E. C., LePera, M. E., and Lestz, S. J. (1989) - "Use of Aviation Turbine Fuel JP-8 as the Single Fuel on the Battlefield" (SAE paper No. 892071, September 1989)

Pulkrabek, W.W. (2004) - "Engineering Fundamentals of the Internal Combustion Engine" (2nd Edition Pearson Prentice Hall)

SAE Standard J1349 (1995) - "Engine Power Test Code - Spark Ignition and Compression Ignition - Net Power Rating" (SAE International, Warrendale, PA) (1995))

Stone R. (2012) - "Introduction to Internal Combustion Engines" 4th Edition (Palgrave MacMillan) ISBN: 9781137028297

Trunzo, M., Schubbe, J., Graham, S. M., \& Caton, P. (2012) - "Integration of Carbon Fibre Composite Materials into AirCooled Reciprocating Piston Engines for UAV Applications" (American Society of Mechanical Engineers ASME 2012 International Mechanical Engineering Congress and Exposition (pp. 943-956)) 